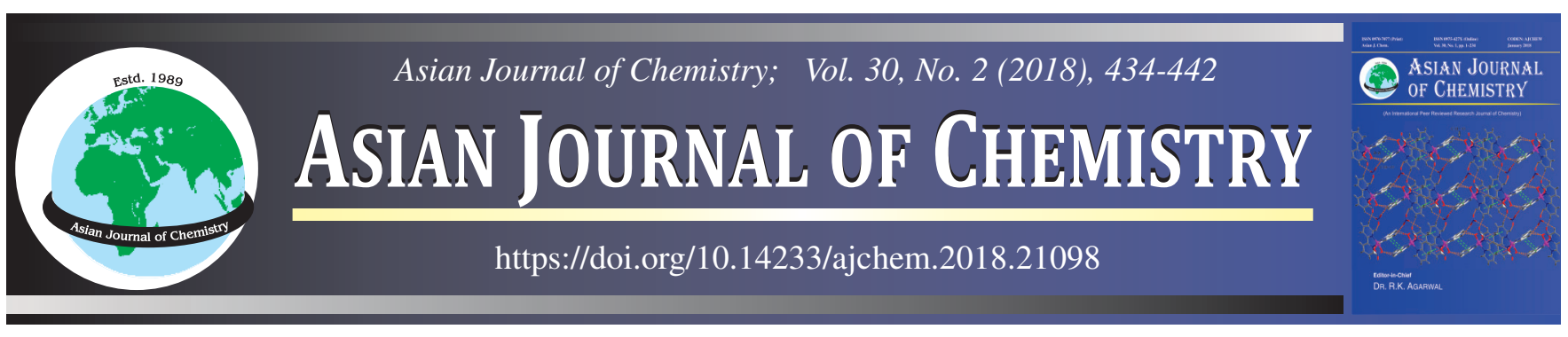

\title{
Catalytic Conversion of Lignin: Studies on Oxidation of Lignin Model Phenolic Monomer over CoMCM-41 and CoMCM-48 Catalysts
}

\author{
R. SAduAL, S. SAHOO and S.K. BADAMALI ${ }^{*}$
}

Department of Chemistry, Utkal University, Vani Vihar, Bhubaneswar-751 004, India

*Corresponding author: Tel/Fax: +91 674 2567734, E-mail: skbuche@utkaluniversity.ac.in

\begin{abstract}
The present study focussed on investigation of the potentiality of cobalt containing mesoporous material (M41S) as a robust heterogeneous catalyst for the oxidation of lignin model phenolic compound. Cobalt containing MCM-41 and MCM-48 were prepared under hydrothermal condition and characterized by various spectroscopic and analytical techniques. Formation of well ordered hexagonal and cubic mesopore structures of MCMs, containing cobalt in the silicate framework was inferred from XRD, TG-DTA and $\mathrm{N}_{2}$ adsorption-desorption studies. DR UV-visible spectral analysis revealed existence of $\mathrm{Co}$ (II) and $\mathrm{Co}(\mathrm{III})$ in the tetrahedral framework. The oxidative ability of CoMCMs were studied for the lignin model phenolic monomer, 1-(4-hydroxy-3-methoxyphenoxy)-ethanol, under mild conditions using environmentally benign $\mathrm{H}_{2} \mathrm{O}_{2}$ as the oxidant. The catalytic results showed that under optimum reaction conditions, apocynol undergoes selective oxidation yielding 2-methoxybenzoquinone and acetovanillone. CoMCM-41 was found to be more selective towards acetovanillone, on the contrary, CoMCM-48 was better catalyst for 2-methoxybenzoquinone yield.
\end{abstract}

Keywords: Lignin, Apocynol, Mesoporous, Methoxybenzoquinine, Acetovanillone.

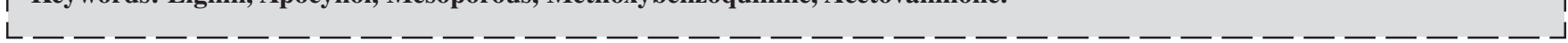

\section{INTRODUCTION}

Lignin is an integral component of plants and is most abundant aromatic biopolymer in earth which can serve as a renewable resource of chemical feedstock. It is suggested that catalytic oxidation of lignin or lignin derived fragments is interesting as it is expected to yield functionalized chemicals which can be employed in fine chemical synthesis [1]. In this subject, several reports have been appeared in literature largely focused on catalytic reactions of lignin model compounds which could provide useful information for the development of selective and high yield processes of lignin oxidation namely the conversion of lignin to aromatic monomers catalyzed by triflic acid [2], depolymerization of oxidized lignin to aromatics by formic acid [3], oxidation of phenolic and non-phenolic compounds in presence of metal chlorides in ionic liquid medium [4] are some of the significant achievements in the area of lignin valorization. Among the lignin model phenolic monomers, apocynol, 1-(4-hydroxy-3-methoxyphenoxy)ethanol is commonly studied over many catalysts. Recently, much attention is focussed on the catalytic oxidation of lignin derived fragments to fine chemicals. Wozniak et al. [5] have studied the liquid phase oxidation of apocynol over potassium nitrosodisulfonate (Fremy's salt) and corresponding benzo- quinones were selectively (about $80 \%$ ) obtained over a reaction period of $2 \mathrm{~h}$. Similarly, 2-methoxybenzoquinone was obtained as the common product from the catalytic oxidation of vanillyl alcohol, resembling a guaiacyl unit of lignin with maximum selectivity of $50 \%$ by using $\mathrm{Co}$ (salen) catalysts and oxygen as oxidant in liquid phase [6]. On the other hand, Canevali and co-workers [7] have successfully carried out the liquid phase oxidation of apocynol in presence of $\mathrm{Co}$ (salen) catalyst under high pressure and 2-methoxybenzoquinone was selectively obtained. The disadvantages of the reported results are the choice of chlorinated solvents, reaction duration, use of auxiliary bases and apply of high pressure, above all separation of the catalyst remains the challenge. Crestini et al. [8] have attempted to overcome these difficulties by performing the reactions over metalloporphyrin supported on montmorillonite catalysts, with the objective of developing a truly heterogeneous catalyst with improved stability. The major difficulty with the study was the reaction being non-selective. In order to address these issues previously we have demonstrated that lignin model phenolic compounds can selectively be transformed to useful chemicals $[9,10]$ over mesoporous SBA-15 heterogeneous catalyst systems.

Over the period, MCMs have emerged as selective heterogeneous catalytic materials having tremendous potential in 
the field of catalysis. Two of the stable members of this family, MCM-41 and MCM-48 have been studied well in the field of catalysis. MCM-48 with its three dimensional pore system has certain advantages for catalytic applications [11-13], as it could allow faster diffusion through the three dimensional channels and make this material less resistant to pore blocking [14]. Similarly, MCM-41 has found to be most studied mesoporous material over last two decades as versatile shape selective catalyst, apart from being an excellent support and adsorbent material $[15,16]$. In particular, the unidimensional tuneable regular pore channel $(2-10 \mathrm{~nm})$, large surface area $\left(\sim 1000 \mathrm{~m}^{2} \mathrm{~g}^{-1}\right)$, good thermal stability as well as a high density of surface silanol (hydroxyl) groups ( 30-40 \%), made this mesoporous material as a potential catalytic system involving bulky organic substrate $[17,18]$. It has been demonstrated that CoMCM-41 and CoMCM-48 shows a good catalytic ability for oxidation of variety of organic substrates including FischerTropsch synthesis [19-21].

We have attempted to screen the oxidative ability of either purely siliceous [22] or cobalt modified mesoporous solids [23] toward lignin model phenolic compounds. With an aim to extend the application of these catalysts for renewable biomass utilization, we have undertaken a study to explore and assess the potential of CoMCM-41 and CoMCM-48 towards selective oxidation of lignin based model molecule. A series of CoMCMs with varying silicon-to-cobalt (molar) ratios by the hydrothermal synthesis route and systematically characterized by using various analytical and spectroscopic techniques. The effect of cobalt content on the textural properties of MCMs has also been investigated. The oxidative ability and stability of the catalyst has been evaluated by performing the liquid phase oxidation of apocynol, an important lignin model phenolic monomer using a clean and environment tolerant oxidant, hydrogen peroxide, under mild reaction conditions.

\section{EXPERIMENTAL}

Preparation of CoMCM-41 mesoporous molecular sieve: A series of CoMCM-41 mesoporous molecular sieves were synthesized by hydrothermal method in a basic medium with the molar ratio of 1.0CTAB: $2.2 \mathrm{Na}_{2} \mathrm{SiO}_{3}: 6.4 \mathrm{EtOH}: 84 \cdot 4 \mathrm{H}_{2} \mathrm{O}$ : $\mathrm{xCoCl}{ }_{2} \cdot 6 \mathrm{H}_{2} \mathrm{O}$, where $\mathrm{x}$ is $0.022,0.036$ and 0.075 , respectively. In a typical synthesis; cetyltrimethylammonium bromide (CTAB) was used as the surfactant, sodium silicate as a source of silica and cobalt chloride as cobalt precursor. First cobalt containing surfactant solution was prepared by the addition of a solution of cobalt chloride in water to the aqueous solution of CTAB and stirred for $30 \mathrm{~min}$. To this mixture ethanol was added and stirred for another $30 \mathrm{~min}$. In another beaker, an aqueous solution of sodium silicate was prepared and stirred for $30 \mathrm{~min}$. This mixture was then added to the surfactant solution, which resulted in a blue coloured gel. The resulting gel solution was then stirred for another $30 \mathrm{~min}$ and then transferred to a Teflon-lined stainless steel autoclave and aged at $373 \mathrm{~K}$ for $72 \mathrm{~h}$. The solid product was recovered by filtration and washed repeatedly with deionized water, followed by drying at $343 \mathrm{~K}$ overnight. The resulting sample was designated as assynthesized CoMCM-41(x), where $\mathrm{x}$ stands for the Si/Co molar ratio in synthesis gel from 100, 60 and 30 respectively. The as-synthesized samples were calcined at $823 \mathrm{~K}$ for $8 \mathrm{~h}$ in flow of nitrogen followed by $2 \mathrm{~h}$ in air.

Preparation of CoMCM-48 mesoporous molecular sieve: A series of CoMCM-48 samples were prepared by hydrothermal synthesis route in a basic medium with cetyltrimethylammonium bromide (CTAB) as the surfactant, tetraethyl orthosilicate (TEOS) as a source of silica and cobalt chloride as cobalt precursors as per the following procedure. First, cobalt containing surfactant solution was prepared by the addition of a solution of cobalt chloride in water to the aqueous solution of $\mathrm{CTAB}$ and stirred for $30 \mathrm{~min}$. In another beaker a mixture containing sodium hydroxide and tetraethyl orthosilicate was prepared and stirred for $5 \mathrm{~min}$. This mixture was then added to the surfactant solution, immediately a blue coloured gel was obtained. The resulting gel was then transferred to a Teflon-lined stainless steel autoclave and aged at $373 \mathrm{~K}$ for $72 \mathrm{~h}$. The solid product was recovered by filtration and repeatedly washed with deionized water, followed by drying at $343 \mathrm{~K}$ overnight. The synthesized gel had a chemical (molar) composition of 1.0CTAB: $1.6 \mathrm{TEOS}: 0.8 \mathrm{NaOH}: 97 \mathrm{H}_{2} \mathrm{O}:(0.0125-$ $0.05) \mathrm{CoCl}_{2} \cdot 6 \mathrm{H}_{2} \mathrm{O}$. The resulting sample is designated as as-synthesized CoMCM-48. The as-synthesized samples were calcined at $823 \mathrm{~K}$ for $3 \mathrm{~h}$ in a flow of nitrogen followed by $3 \mathrm{~h}$ in air.

Preparation of apocynol: Apocynol was synthesized as per the procedure outlined elsewhere [24] and characterized by melting point, ${ }^{1} \mathrm{H},{ }^{13} \mathrm{C}$ NMR, GC and GC-MS studies.

Characterization of the catalysts: The synthesized materials were characterized by various spectroscopic and analytical techniques. Powder X-ray diffraction (XRD) patterns were recorded using Brucker D8 diffractometer with $\mathrm{CuK}_{\alpha}$ radiation. Diffuse reflectance ultraviolet and visible (DRUV-vis) spectra were recorded in the range 200-800 nm on Shimadzu 2450 using $\mathrm{BaSO}_{4}$ as the reference. Fourier transform infrared (FT-IR) spectra were recorded in a Perkin-Elmer Paragon-500 spectrometer in $\mathrm{KBr}$ medium. The cobalt content in the synthesized sample was measured by atomic absorption spectroscopy (AAS, Shimadzu AA-6300). BET-surface area and pore size were measured by using ASAP 2020, Micromeritics analytical system.

Catalytic activity studies: In a typical catalytic reaction, apocynol (1.0 mmol, $168 \mathrm{mg})$, acetonitrile $(5 \mathrm{~mL})$, the catalyst (100 mg) and $35 \%$ aqueous $\mathrm{H}_{2} \mathrm{O}_{2}(3.0 \mathrm{mmol}, 0.4 \mathrm{~mL})$ were placed in a round bottomed flask and allowed to react with varying reaction temperature and duration. Prior to the recycling experiments the spent catalyst was activated by heating at 773 $\mathrm{K}$ for $6 \mathrm{~h}$ in flowing air. Recycling tests were conducted for five times following typical reaction conditions.

GC analyses were carried out on a Varian-450 instrument, equipped with a VF-1 $\mathrm{ms}$ column $(15 \mathrm{~m} \times 0.25 \mathrm{~mm} \times 0.39 \mathrm{~mm}$ film thickness) and flame ionization detector (FID) using nitrogen as the carrier gas. The initial column injector was set to $473 \mathrm{~K}$ with an initial column temperature of $333 \mathrm{~K}$, raised to $423 \mathrm{~K}$ with a ramp rate of $288 \mathrm{~K} \mathrm{~min}^{-1}$ and then to $533 \mathrm{~K}$ at $283 \mathrm{~K} \mathrm{~min}^{-1}$. Substrate conversion and product yield were determined using an external standard method, according to the method reported earlier [24].

\section{RESULTS AND DISCUSSION}

Catalyst characterization: The colour of the as-synthesized CoMCM-48 as well as CoMCM-41was light pink in 
colour, however, after calcination the sample turned to pale blackish colour in case of CoMCM-48 and blue colour in case of CoMCM-41. Usually such a change in colour is correlated with variation in the oxidation state and coordination of cobalt. Blue colour of the CoMCM-41 sample was assigned to the tetrahedral $\mathrm{Co}$ (II) [25] and pale blackish is assigned to the mixture of both $\mathrm{Co}(\mathrm{II})$ and $\mathrm{Co}(\mathrm{III})$ [26], means the possible formation of mixed spinel oxide $\mathrm{Co}_{3} \mathrm{O}_{4}$. The cobalt content in the calcined CoMCM-48 material was found to be 1.14-3.63 $\mu \mathrm{mol}$ per gram of catalyst and that for CoMCM-41 was 0.93.13 for various silicon-to-cobalt molar ratio in the gel.

Powder X-ray diffraction: The low angle XRD patterns of the calcined CoMCM-48 and CoMCM-41 are shown in Figs. 1 and 2. In case of siliceous MCM-48 sample (Fig. 1a), strong reflections observed in between $2 \theta=2$ to $3^{\circ}$ in addition to several weak reflection in the range of $2 \theta=3$ to $7^{\circ}$ indicates the formation of ordered mesoporous structure [27]. Similar patterns in the small angle XRD patterns were noticed after incorporation with cobalt (Fig. 1b), demonstrating the preservation of the cubic mesoporous structure of the parent material.
Similarly, it has been shown from the Fig. 2a that, MCM-41 exhibited a high-intensity reflection related to the (100) plane at $2 \theta=2.1^{\circ}$ and have small and weak diffraction peaks at $2 \theta$ value ranging from 3.4 to $6^{\circ}$ corresponding for the (110), (200), (210) planes respectively, which is consistent with the characteristic diffraction patterns of the hexagonal mesoporous molecular sieve [28]. This indicates the formation of a highly ordered structure of a hexagonal pore arrays. In cobalt incorporated MCM-41 Fig. 2b, four reflection peaks, characteristic of the hexagonal mesoporous structure, were clearly seen although the intensity is less when compared with pure MCM-41. In both cases it has been observed that the unit cell parameter $\left(\mathrm{a}_{\mathrm{o}}\right)$ of cobalt modified samples was shifted to higher values as compare to that of the pure siliceous samples. This could be mainly due to the large atomic size of $\mathrm{Co}^{2+}(0.72 \AA)$ as compared with $\mathrm{Si}^{4+}$ (atomic radius of $0.40 \AA$ ), leading to a longer Co-O distance. Moreover, these observations suggest the successful incorporation of cobalt into the silica framework [29]. The hexagonal unit cell parameter $\left(a_{0}\right)$, calculated by the formula $\mathrm{a}_{0}=2 \mathrm{~d}_{100} / \sqrt{3}$ and the cubic unit cell parameter $\left(\mathrm{a}_{\mathrm{o}}\right)$,
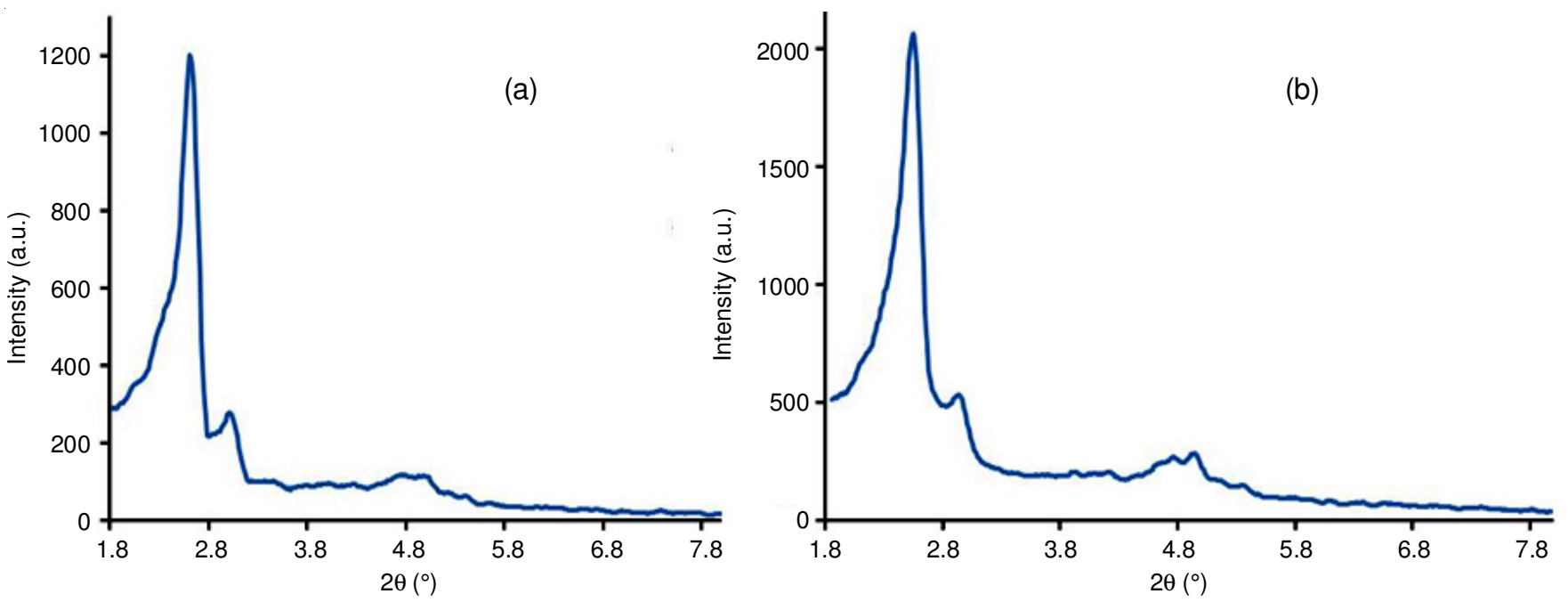

Fig. 1. XRD patterns of calcined MCM-48 (a) and CoMCM-48 (b)
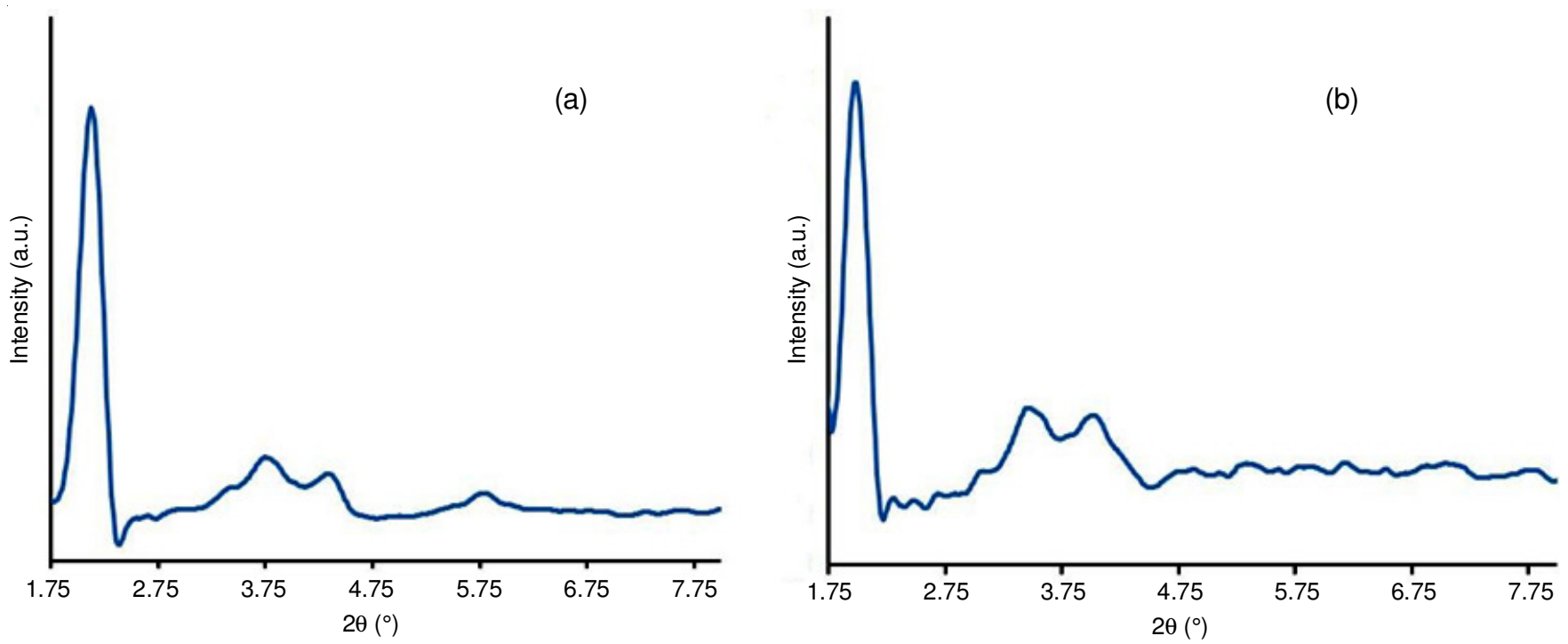

Fig. 2. XRD patterns of calcined MCM-41 (a) and CoMCM-41(b) 
calculated by the formula $\mathrm{a}_{0}=2 \mathrm{~d}_{211} / \sqrt{ } 6$ and d-spacing calculated by the formula $2 \mathrm{~d} \sin \theta=\mathrm{n} \lambda$ are listed in Table- 1 . The wideangle XRD patterns of the CoMCM-48 and CoMCM-41 samples are shown in Figs. 3 and 4, respectively. A broad diffraction peak between $57-60^{\circ}$ has appeared in case of CoMCM-48, which corresponds to (511) reflection of nano-crystallite $\mathrm{Co}_{3} \mathrm{O}_{4}$ (according to card no. JCPDS 78-1970) highly dispersed in the molecular sieve frame work of MCM-48. However, absence of peaks corresponding to oxides of cobalt in case of CoMCM41 indicates either the crystalline size of metal oxides is below the lower limit for XRD detectability or an amorphous metal oxide highly dispersed in the molecular sieve framework of MCM-41 is formed [30].

TABLE-1

TEXTURAL PROPERTIES OF COMCM-48 AND CoMCM-41

\begin{tabular}{lccc}
\hline Material & $\begin{array}{c}\text { Surface area } \\
\left(\mathrm{m}^{2} \mathrm{~g}^{-1}\right)\end{array}$ & $\begin{array}{c}\text { Pore volume } \\
\left(\mathrm{cm}^{3} \mathrm{~g}^{-1}\right)\end{array}$ & $\begin{array}{c}\text { Pore diameter } \\
(\mathrm{nm})\end{array}$ \\
\hline MCM-48 & 978 & 0.50 & 2.60 \\
CoMCM-48 & 1014 & 0.70 & 3.30 \\
MCM-41 & 1339 & 0.73 & 2.35 \\
CoMCM-41 & 860 & 0.50 & 2.47 \\
\hline
\end{tabular}

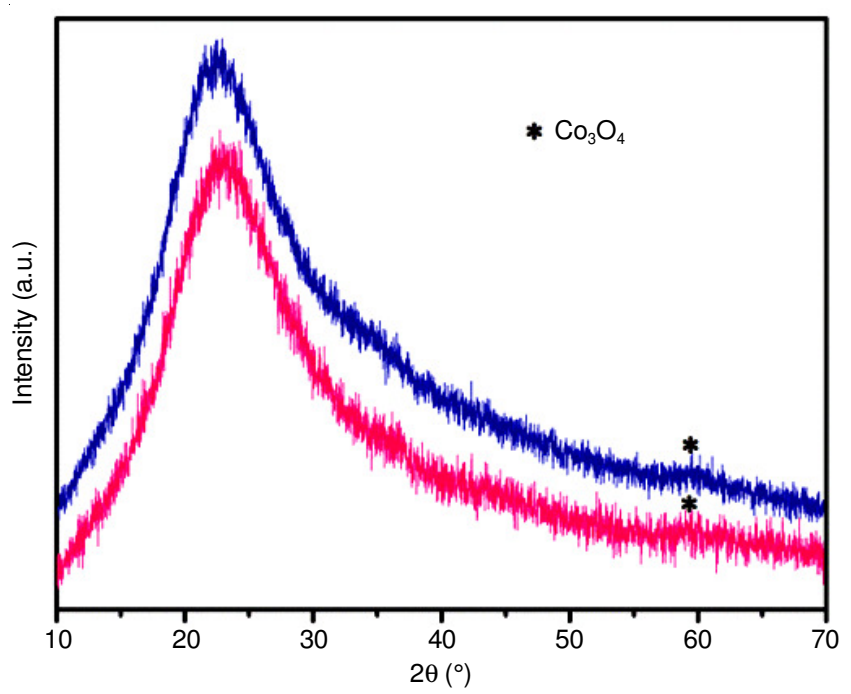

Fig. 3. XRD patterns in higher $2 \theta$ range of calcined CoMCM-48 (32) (blue) and CoMCM-48 (64) (pink)

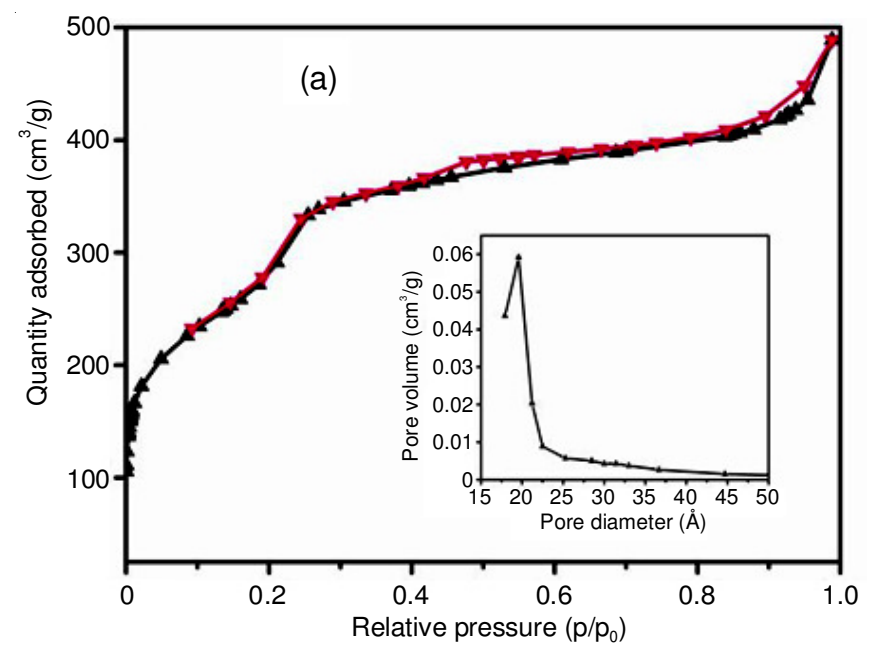

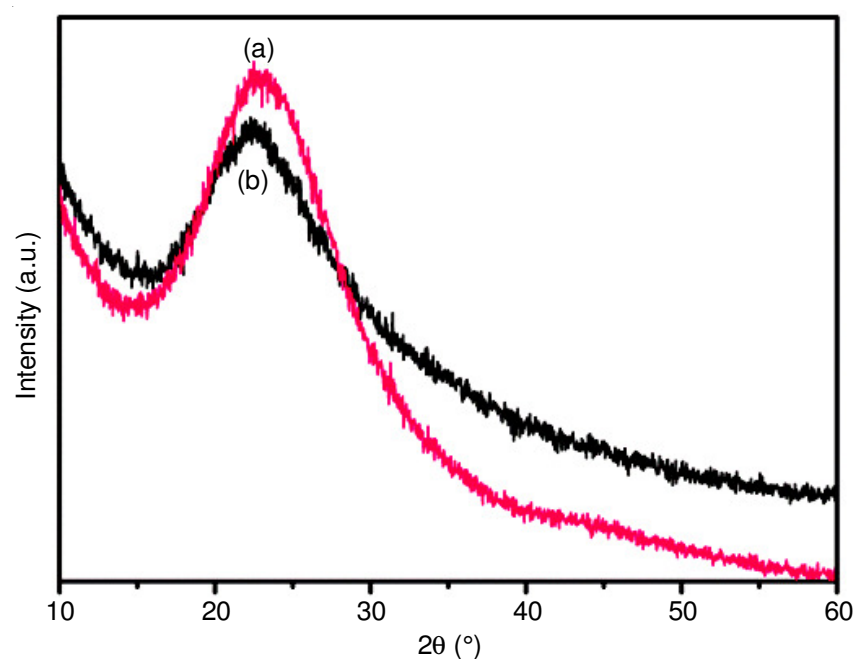

Fig. 4. XRD patterns in higher $2 \theta$ range of calcined MCM-41 (a) and CoMCM-41 (b)

$\mathbf{N}_{2}$ adsorption-desorption studies: Fig. 5(a,b) shows the nitrogen adsorption-desorption results of CoMCM-48(a) and CoMCM-41(b) respectively. And the pore size distribution curves were obtained from desorption branch using BJH method and are shown inset. Textural properties of both the samples are listed in Table-1. Both the samples show type IV adsorption isotherms (IUPAC) belonging to a typical mesoporous materials [31-33] with a sharp inflection between the relative pressure $\left(0.1<\mathrm{p} / \mathrm{p}_{\mathrm{o}}<0.35\right)$, which is due to the capillary condensation of nitrogen within the mesopores [34]. The sharpness of this step reflects the uniform pore size in these materials [35]. As shown in the figure the isotherms of CoMCM-48 also contain a $\mathrm{H} 3$ hysteresis loop at relative pressure of above 0.8 , indicating a partial loss in the ordering of the pore channel. It has been observed in both cases that there is an increment of pore size after incorporation of cobalt into the siliceous material (not reproduced here), suggesting the possible distortion of the silica framework. This may be due to the fact that $\mathrm{Co}-\mathrm{O}$ bond length is longer than that of $\mathrm{Si}-\mathrm{O}$, presumably which leads to an increase of the pore size.

Diffuse Reflectance UV-visible spectroscopy (DRUVvis): The diffuse reflectance UV-visible spectra, recorded at room temperature are used for the identification of metal ion

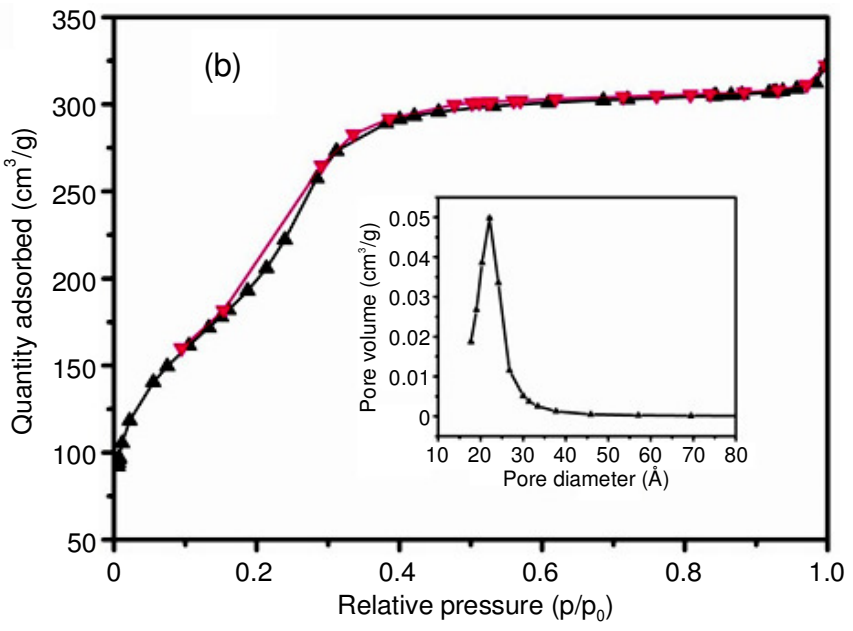

Fig. 5. $\mathrm{N}_{2}$ adsorption-desorption isotherms and pore size distributions curve (inset) of calcined CoMCM-48 (a) and CoMCM-41(b) 
existence in the framework of metal-containing mesoporous materials. Figs. 6 and 7 depicts the DRUV-visible spectra of the calcined CoMCM-48 and CoMCM-41, respectively. For a comparison, the spectrum of siliceous materials is also included. The appearance of bands in between $300-800 \mathrm{~nm}$ in case of cobalt containing materials, against a little absorbance noticed for siliceous material in this region suggested the fact that incorporation of cobalt in the silica structure. Both the calcined cobalt containing samples exhibit absorption band in the region of 220-285 nm that can be assigned to charge transfer transitions from oxygen to $\mathrm{Co}(\mathrm{II})$ ion [36], possibly $\mathrm{Co}(\mathrm{II})$ ions are present in a tetrahedral coordination. Furthermore, the observed bands located in the 500-650 $\mathrm{nm}$ region (shown in inset) in case of both the calcined samples correspond to the $d$ - $d$ transitions of $\mathrm{Co}(\mathrm{II})$ ions [37] in tetrahedral geometry. Upon calcination a part of $\mathrm{Co}$ (II) has been oxidized to $\mathrm{Co}$ (III), which shows a broad band at $465 \mathrm{~nm}$ attributed to octahedral coordination of $\mathrm{Co}$ (III), in case of cobalt containing MCM-48 material. Due to the appearance of these bands, formation of mixed oxide of cobalt, $\mathrm{Co}_{3} \mathrm{O}_{4}$ cannot be excluded. However no such evidence was noticed in CoMCM-41 materials, indicate the presence of Co(II) predominantly in tetrahedral environment in the matrix.

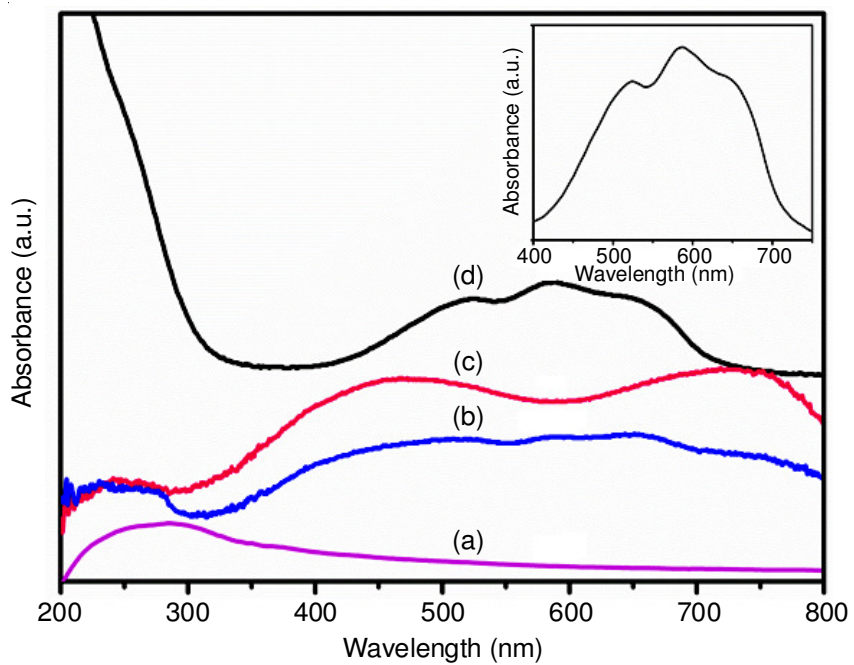

Fig. 6. DRUV-visible absorption spectra of calcined: (a) MCM-48; (b) CoMCM-48 (128); (c) CoMCM-48 (64) and (d) CoMCM-48 (32)

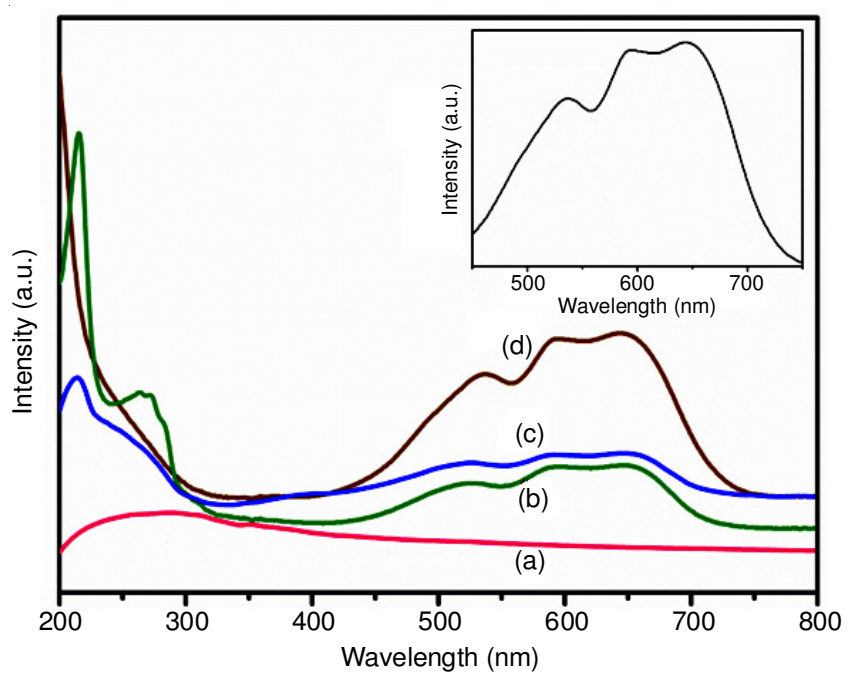

Fig. 7. DRUV-visible absorption spectra of calcined: (a) MCM-41; (b) CoMCM-41 (100); (c) CoMCM-41(60) and (d) CoMCM-41 (30)
Fourier transform infrared (FT-IR) spectroscopy: FTIR spectra of both calcined CoMCM-48 and CoMCM-41 samples with different ratio of silicon to cobalt along with siliceous samples are shown in Figs. 8 and 9 respectively. The characteristic band for surfactant template, CTAB, at 2928, 2854 and $1490 \mathrm{~cm}^{-1}$ [38] disappeared in the calcined spectra. However other characteristic peaks for the corresponding materials are found to present. It indicates the mesoporous structure of the samples remains unchanged after calcination. A broad band observed between $3800-3000 \mathrm{~cm}^{-1}$ can be assigned to the $\mathrm{O}-\mathrm{H}$ stretching vibrations of the surface silanols along with an intense band at around $1645-1625 \mathrm{~cm}^{-1}$ from vibration of adsorbed water molecules. The intensity of these peaks in case of calcined spectra is a clear evidence of the hydrophilic nature of the calcined materials. Absorption bands noticed at 1082, 808 and $460 \mathrm{~cm}^{-1}$ are attributed to the asymmetric, symmetric stretching and bending vibration for $\mathrm{Si}-\mathrm{O}-\mathrm{Si}$ bonds [39] respectively. These bands are found to be present both in the parent siliceous as well as in all cobalt incorporated samples, which indicate that silica framework was not affected after modification, which correlates with the XRD results. Furthermore an additional band at around $965 \mathrm{~cm}^{-1}$ noticed in all the

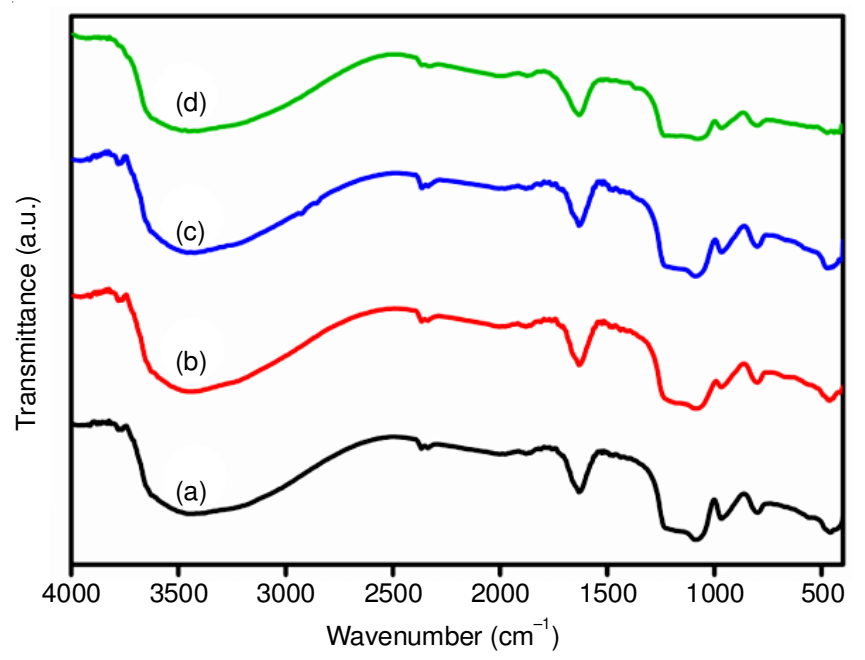

Fig. 8. FT-IR spectra of calcined: (a) MCM-48; (b) CoMCM-48 (32); (c) CoMCM-48 (64) and (d) CoMCM-48(128)

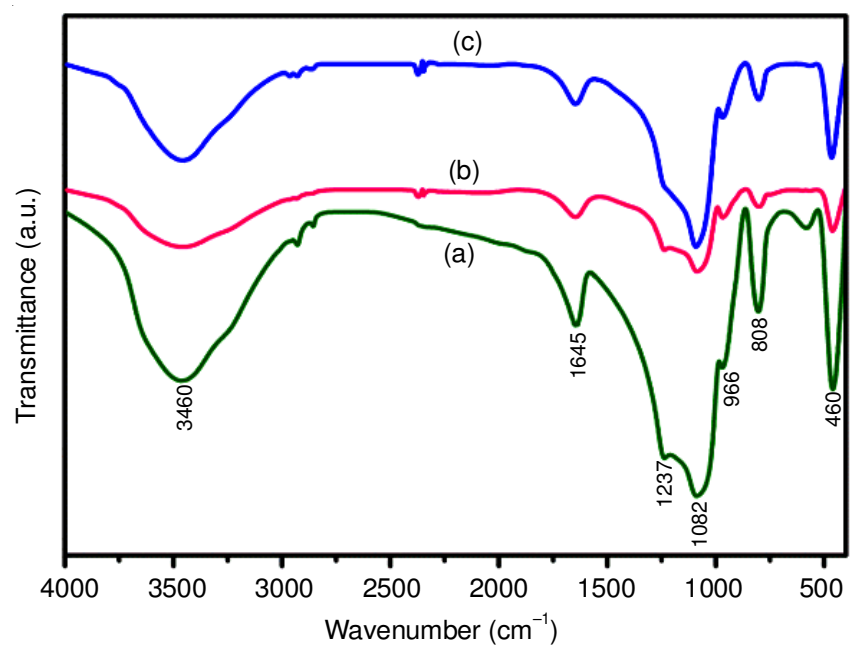

Fig. 9. FT-IR spectra of calcined: (a) MCM-41; (b) CoMCM-41 (100) and (c) CoMCM-41 (60) 
spectra of siliceous as well as in all cobalt incorporated samples can be assigned to the stretching vibration of $\mathrm{Si}-\mathrm{O}-\mathrm{Si}$ and $\mathrm{Si}-\mathrm{O}-$ Co bond [40]. Interestingly, it has been observed that $\mathrm{v}(\mathrm{O}-\mathrm{H})$ $(\mathrm{Si}-\mathrm{OH})$ intensity gradually increased with an increase in cobalt content in case of CoMCM-41 (Fig. 9) sample and such a trend is attributed to the possible prevention in the condensation of silanol groups by the insertion of cobalt. However, $v(\mathrm{O}-\mathrm{H})$ $(\mathrm{Si}-\mathrm{OH})$ intensity was not affected as a function of cobalt content in case of CoMCM-48 sample (Fig. 8).

Catalytic activity study: Catalytic activity of CoMCM-48 and CoMCM-41 was evaluated by investigating the oxidation of apocynol, 1-(4-hydroxy-3-methoxyphenoxy)ethanol (1) using $\mathrm{H}_{2} \mathrm{O}_{2}$ as the oxidant under varying reaction conditions, Scheme-I and the results are summarized in Tables 2 and 3. In order to understand the role of siliceous matrix alone, the reaction was also studied over the siliceous MCM-48 and MCM-41.

The results showed that upon oxidation apocynol produced both 2-methoxybenzoquinone (2) and acetovanillone (3). It is worth mentioning that, benzoquinones are found to be a key intermediates in various organic reactions [41] and acetovanillone is the precursor for the production of fine chemicals such as acetoveratron, veratric acid and veratric acid chloride [42]. Reaction was studied over 15-180 min duration

TABLE-2

REACTION PROFILE OF APOCYNOL OVER COMCM-41

\begin{tabular}{clcccc}
\hline \multirow{2}{*}{$\begin{array}{c}\text { S. } \\
\text { No. }\end{array}$} & Catalyst & \multirow{2}{*}{$\begin{array}{c}\text { Duration } \\
(\mathrm{min})\end{array}$} & $\begin{array}{c}\text { Conversion } \\
(\%)\end{array}$ & \multicolumn{2}{c}{$\begin{array}{c}\text { Product distri- } \\
\text { bution }(\%)\end{array}$} \\
\cline { 5 - 6 } & & & & $(\mathbf{2})$ & $(\mathbf{3})$ \\
\hline $1^{\text {a }}$ & Blank & 180 & - & - & - \\
2 & MCM-41 & 15 & 84 & 65 & 19 \\
3 & MCM-41 & 30 & 96 & 77 & 4 \\
4 & MCM-41 & 60 & 98 & 80 & - \\
5 & MCM-41 & 180 & $>99$ & 84 & - \\
$6^{b}$ & Absent & 15 & 80 & 22 & 15 \\
7 & CoMCM-41(30) & 15 & 53 & 28 & 6 \\
8 & CoMCM-41 (30) & 30 & 85 & 31 & 18 \\
9 & CoMCM-41(30) & 60 & 87 & 40 & 47 \\
10 & CoMCM-41 (30) & 180 & 90 & 43 & 52 \\
11 & CoMCM-41 (60) & 180 & 89 & 44 & 46 \\
12 & CoMCM-41 (100) & 180 & 84 & 40 & 34 \\
\hline
\end{tabular}

Reaction conditions: $1.0 \mathrm{mmol}$ apocynol, $3 \mathrm{mmol} \mathrm{H}_{2} \mathrm{O}_{2}, 5 \mathrm{~mL}$ acetonitrile, $100 \mathrm{mg}$ catalyst at $313 \mathrm{~K}$, duration $15-180 \mathrm{~min}$.

${ }^{\mathrm{a}} 1$ in acetonitrile; ${ }^{\mathrm{b}} 1$ in acetonitrile and oxidant.

"The numbers in the parentheses indicates the silicon-to-cobalt molar ratio in the gel.

\section{TABLE-3}

REACTION PROFILE OF APOCYNOL OVER COMCM-48

\begin{tabular}{clcccc}
\hline \multirow{2}{*}{$\begin{array}{c}\text { S. } \\
\text { No. }\end{array}$} & Catalyst & \multirow{2}{*}{$\begin{array}{c}\text { Duration } \\
(\mathrm{min})\end{array}$} & $\begin{array}{c}\text { Conversion } \\
(\%)\end{array}$ & \multicolumn{2}{c}{$\begin{array}{c}\text { Product distri- } \\
\text { bution (\%) }\end{array}$} \\
\cline { 5 - 6 } & & & & $(\mathbf{2})$ & $(\mathbf{3})$ \\
\hline 1 & MCM-48 & 15 & 95 & 65 & 16 \\
2 & MCM-48 & 30 & 94 & 67 & - \\
3 & MCM-48 & 60 & 94 & 39 & - \\
4 & MCM-48 & 180 & $>99$ & 40 & - \\
5 & CoMCM-48 (32) & 15 & 87 & 16 & 13 \\
6 & CoMCM-48 (32) & 30 & 88 & 30 & 4 \\
7 & CoMCM-48 (32) & 60 & 85 & 36 & - \\
7 & CoMCM-48 (32) & 180 & 86 & 38 & - \\
8 & CoMCM-48 (64) & 180 & 87 & 41 & - \\
9 & CoMCM-48 (128) & 180 & 87 & 40 & - \\
10 & Co(NO $\left.{ }_{3}\right)_{2} \cdot 6 \mathrm{H}_{2} \mathrm{O}$ & 180 & 93 & 30 & - \\
\hline
\end{tabular}

Reaction conditions: $1.0 \mathrm{mmol}$ apocynol, $3 \mathrm{mmol} \mathrm{H}_{2} \mathrm{O}_{2,} 5 \mathrm{~mL}$ acetonitrile, $100 \mathrm{mg}$ catalyst at $313 \mathrm{~K}$, duration 15-180 min.

${ }^{\mathrm{a}} 1$ in acetonitrile; ${ }^{\mathrm{b}} 1$ in acetonitrile and $\mathrm{H}_{2} \mathrm{O}_{2}$

"The numbers in the parentheses indicates the silicon-to-cobalt molar ratio in the gel.

and from the observed reactivity it is well evident that apocynol is quite stable under the reaction condition irrespective of $3 \mathrm{~h}$ of heating in the solvent (Table-2, entry 1). However, in presence of hydrogen peroxide mixture of 2-methoxybenzoquinone, acetovanillone and high molecular weight compounds (unidentified) were obtained (entry 6). Interestingly the reaction proceeded in a remarkable manner by using the siliceous either MCM-41 or MCM-48 with a substrate conversion of $>80 \%$ within 15 min of reaction and selective towards 2-methoxybenzoquinone (Table-2, entry 2). Recently, we have observed that mesoporous silicas can catalyse the reaction yielding selectively methoxybenzoquinone [20]. Further we have observed that apocynol (1) is susceptible to oxidation in presence of $\mathrm{H}_{2} \mathrm{O}_{2}$ alone and the reaction proceeds in an uncontrolled and non-selective manner resulting in several high molecular weight products (not identified). The tabulated results of the reaction catalyzed by cobalt modified materials reveal that the reaction becomes less selective in presence of CoMCM48 and CoMCM-41 as catalyst in general. However, the selectivity towards 2-methoxybenzoquinone remains almost unchanged with varying cobalt content in both cases. Interestingly, selectivity towards acetovanillone was found to be enhanced with varying cobalt content in case of CoMCM-41. On the other hand, over CoMCM-48, selectively (2) was obtained despite an increase in cobalt content. Reaction carried out over CoMCM-
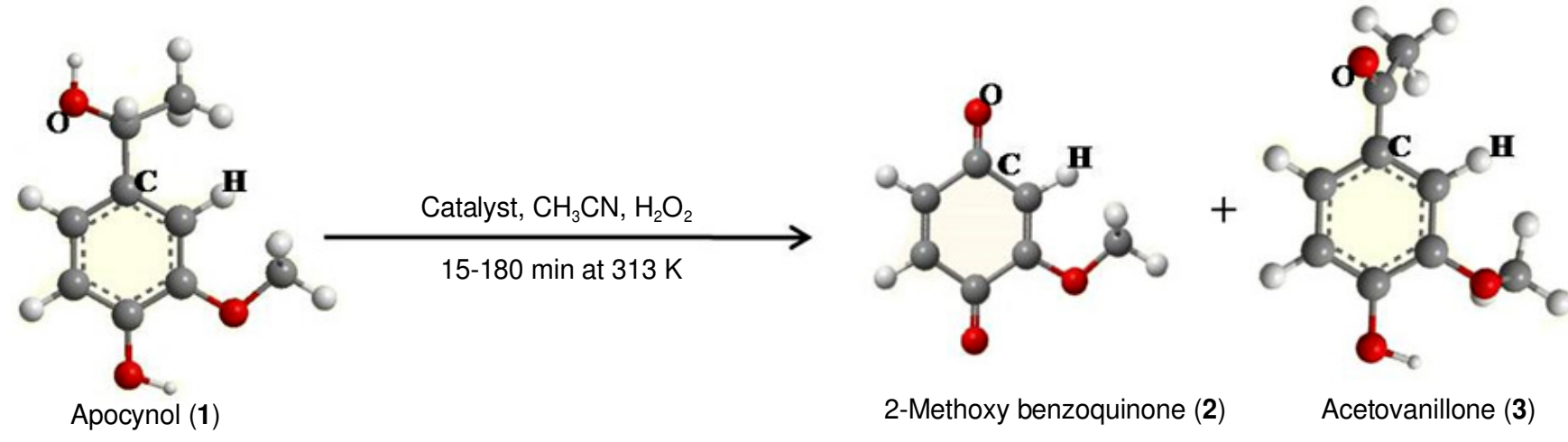

Scheme-I: Reaction profile of oxidation of apocynol (1) over cobalt modified catalysts 
48 from 15-180 min showed similar percentage of substrate conversion along with a marginal increase in 2-methoxybenzoquinone selectivity. However, using CoMCM-41 as catalyst both apocynol conversion and selectivity of products were increased with increase of reaction duration. To evaluate the role of $\mathrm{Co}$ (II) ions alone, reactions were conducted using cobalt nitrate in homogeneous medium and achieved $>90 \%$ substrate conversion with selective formation of 2-methoxybenzoquinone (Table-3, entry 10).

Although it is premature to comment upon the exact mechanism of the reaction over cobalt modified materials, based on the results obtained, assuming $\mathrm{Co}$ (II) as an active species for such type of product profile, we propose a plausible pathway for the formation of the products over the catalysts. Cobalt(II) present in the catalyst, interacts with the hydrogen peroxide yielding hydroxyl radical $[43,44]$. Subsequently, the reaction proceeds in two possible pathways, the hydroxy radical formed either abstracts a phenolic hydrogen atom from the phenolic substrate (1) (path-1) and produces a reactive phenoxy radical (4) or it abstracts a proton from the benzylic carbon (path-2), forming the reactive radical (6). By the path-1, (4) transformed to intermediate (5), through addition of another hydroxyl radical. Intermediate $\mathbf{5}$, undergoes rearrangement to form 2-methoxybenzoquinone (2). On the other hand, through path-2, intermediate $\mathbf{6}$ undergoes deprotonation via another hydroxy radical leading to the formation of acetovanillone (3) (Scheme-II).

It is quite understandable that hydrogen peroxide can be activated either by cobalt [20] or silanol groups [44] to generate hydroxyl radicals which catalyzes the reaction. Presence and involvement of multiple active sites such as oxidant, cobalt and silanol groups makes the reaction non-selective. CoMCM-
41 containing silanol groups as well as $\mathrm{Co}(\mathrm{II})$ yields mixture of products $\mathbf{2}$ and $\mathbf{3}$. Increment of $\mathrm{OH}$-groups with increase in cobalt content in CoMCM-41 can lead to proton extraction both from benzylic carbon as well as from phenolic substrate. As a result both the products ( 2 and $\mathbf{3}$ ) are possible. On the other hand, 2-methoxybenzoquinone was found as the oxidation product from the reaction catalyzed by CoMCM-48 having silanol groups along with $\mathrm{Co}(\mathrm{II})$ and $\mathrm{Co}(\mathrm{III})$. And also there is a relatively lesser effect on $\mathrm{OH}$-group intensity with increase in cobalt content in CoMCM-48.

The results obtained from the present investigation indicate the fact that the reaction proceeds simultaneously both in homogeneous and heterogeneous medium. In order to verify the heterogeneous nature of the catalyst, (i.e. leaching of cobalt from the matrix during reaction) oxidation reaction of apocynol was carried out with the treated catalyst under identical conditions. In a typical reaction, the catalyst CoMCM-41 was stirred with solvent and oxidant at $323 \mathrm{~K}$ for $3 \mathrm{~h}$ and filtered. Oxidation of $\mathbf{1}$ was then carried out both with the residue and filtrate. To the filtrate, substrate and oxidant were added and the reaction was allowed to run for $3 \mathrm{~h}$. In a separate experiment the residue was used as catalyst and the reaction was carried out with the addition of substrate, solvent and oxidant. The observed results are tabulated in Table-4. It was noticed that, conversion and selectivity towards 2-methoxybenzoquinone are close to that obtained from the use of cobalt salt in homogeneous medium. This significant activity of the filtrate indicated the leaching out of cobalt species from the catalyst into the medium. For further confirmation, the filtrate was analyzed by AAS for the estimation of cobalt. The leached cobalt amounting to $0.33 \mathrm{ppm}$ (for CoMCM-48) and 0.30 ppm (for CoMCM-41), confirmed the leaching of cobalt from the catalyst during reaction. The

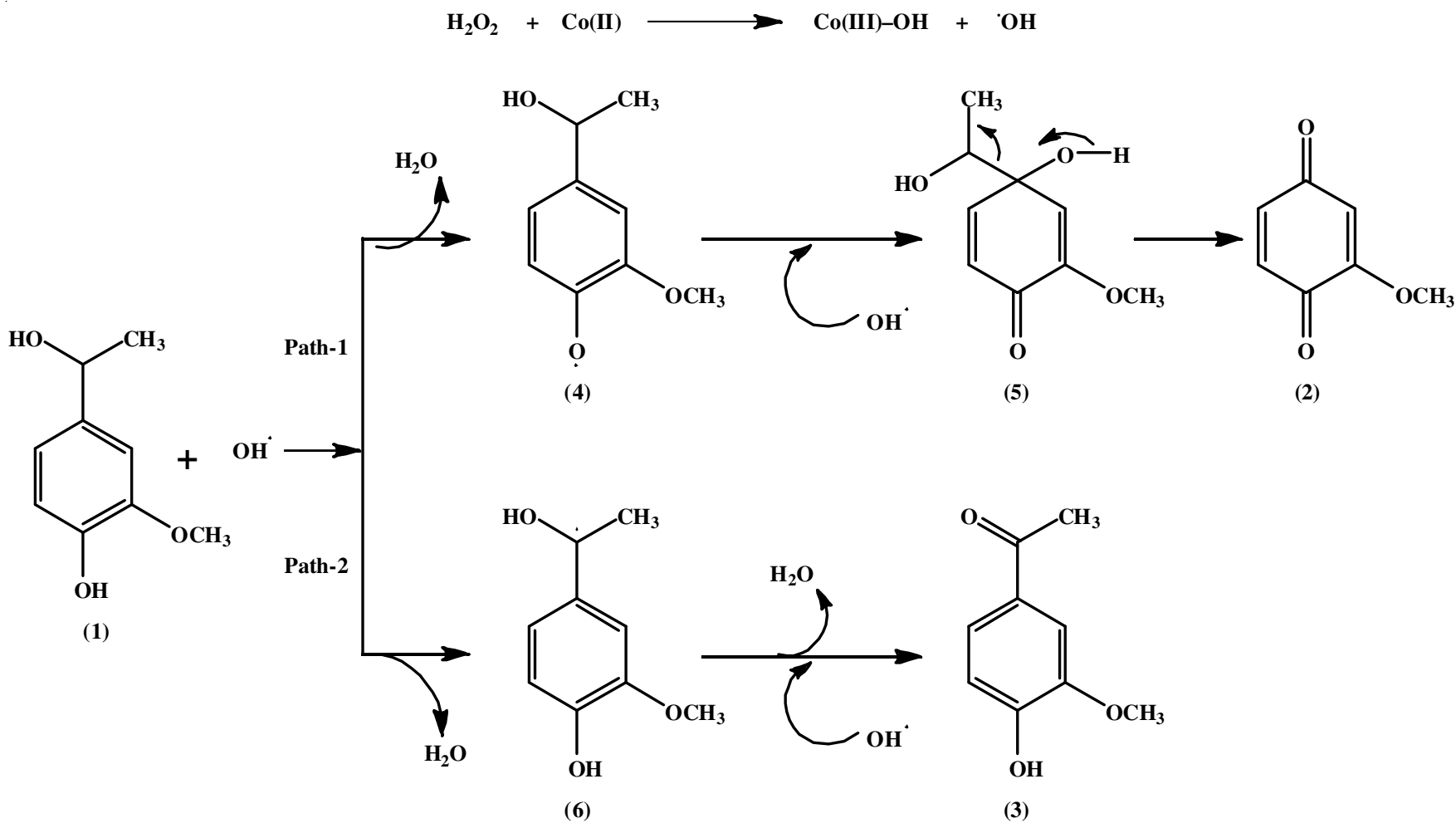

Scheme-II: Probable oxidation pathway of (1) over cobalt containing catalyst 


\begin{tabular}{|c|c|c|c|c|}
\hline \multirow{3}{*}{ Entry } & \multicolumn{4}{|c|}{$\begin{array}{c}\text { TABLE-4 } \\
\text { OXIDATION OF APOCYNOL OVER } \\
\text { TREATED CoMCM-41 AND CoMCM-48 }\end{array}$} \\
\hline & \multirow{2}{*}{ Catalyst* } & \multirow{2}{*}{$\begin{array}{c}\text { Conversion } \\
(\%)\end{array}$} & \multicolumn{2}{|c|}{ Product distribution (\%) } \\
\hline & & & (2) & (3) \\
\hline 1 & CoMCM-41(F) & 90 & 32 & - \\
\hline 2 & CoMCM-41(R) & 90 & 40 & 42 \\
\hline 3 & CoMCM-48 (F) & 90 & 29 & - \\
\hline 4 & CoMCM-48 (R) & 93 & 40 & - \\
\hline \multicolumn{5}{|c|}{$\begin{array}{l}\text { Reaction conditions: } 1.0 \mathrm{mmol} \text { apocynol, } 3 \mathrm{mmol} \mathrm{H}_{2} \mathrm{O}_{2 .} 5 \mathrm{~mL} \\
\text { acetonitrile, } 100 \mathrm{mg} \text { catalyst at } 313 \mathrm{~K} \text {, duration } 15-180 \mathrm{~min} . \\
\text { "F-Filtrate, R-Residue }\end{array}$} \\
\hline
\end{tabular}

residue, containing the remaining cobalt was also active to catalyze the reaction.

Recycling studies of both the catalyst was conducted for five times following the similar reaction condition. The spent catalyst was recovered from the reaction mixture by filtration and recycled by washing with dichloromethane repeatedly followed by activation i.e., by heating at $773 \mathrm{~K}$ for $6 \mathrm{~h}$ in flowing air. Catalytic reactions were conducted over regenerated catalyst and the catalysts were found to nearly constant for both substrate conversion and product yield at least upto five runs (Figs. 10 and 11).

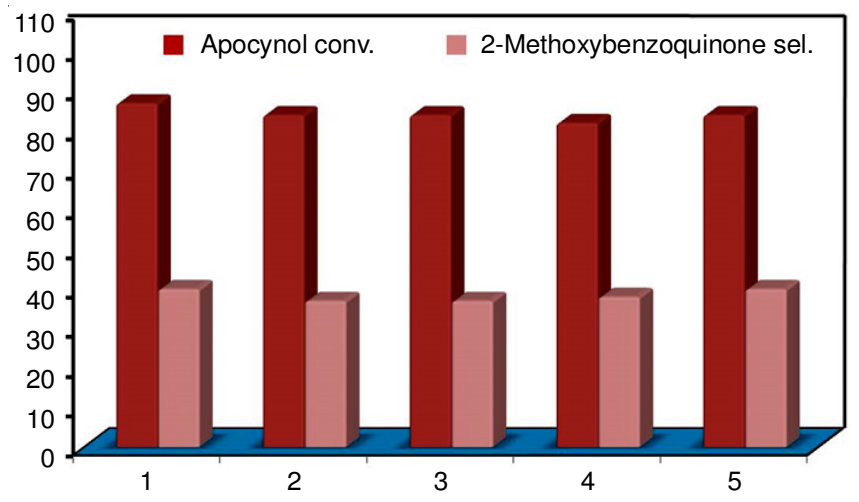

Fig. 10. Recyclability test of CoMCM-48

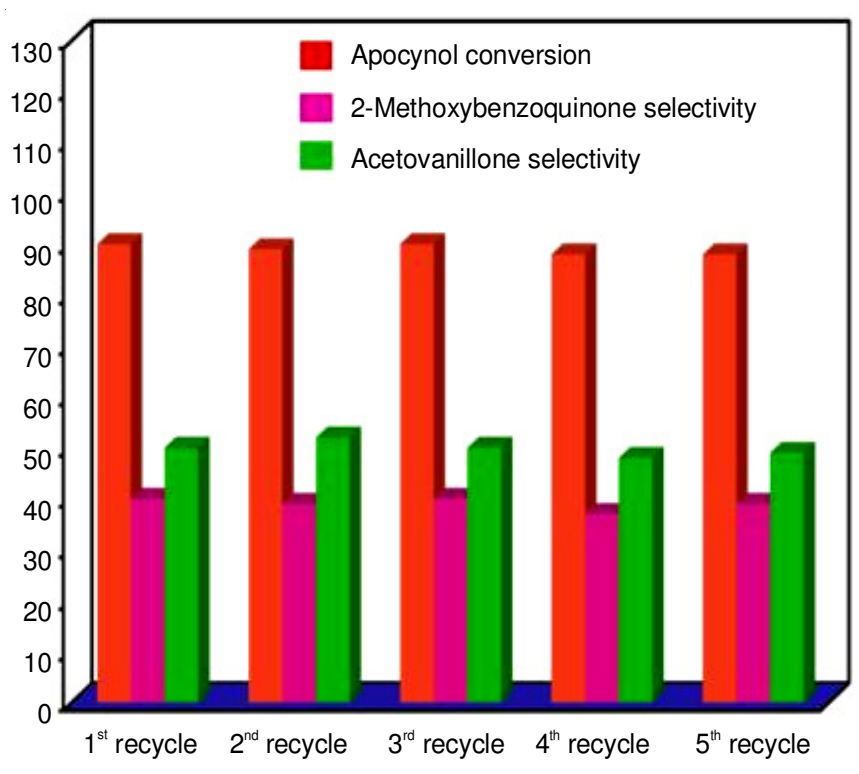

Fig. 11. Recyclability test of CoMCM-41

\section{Conclusion}

A series of cobalt containing mesoporous catalysts is prepared via direct hydrothermal synthetic route and evaluated catalytic performance of catalyst for the oxidation of an important lignin model phenolic monomer under varying reaction conditions. The catalytic activity results showed that under the optimum reaction condition apocynol undergoes selective oxidation, yielding 2methoxybenzoquinone and acetovanillone. It was observed that with increase in the cobalt amount there is an increment in the acetovanillone yield in case of CoMCM-41. On the other hand, CoMCM-48 is more selective towards 2-methoxybenzoquinone under the present reaction conditions. Cobalt(II) present in the catalyst is suspected to be responsible for such activity. The intensity of silanol groups has increased with an increase in cobalt content in CoMCM-41. It is correlated that $\mathrm{Co}$ (II), $\mathrm{H}_{2} \mathrm{O}_{2}$ and silanol groups are responsible for the observed activity. Combining with FT-IR results, it is assumed that presence of more silanol groups is responsible for the reaction to proceed following path-2. Further, leaching of cobalt from CoMCM-41 and CoMCM-48 into the medium during the reaction was noticed during initial catalytic run. Subsequently, the catalysts were recycled and reused for five times without any significant loss in activity and selectivity demonstrating the heterogeneous nature of catalyst in subsequent runs.

\section{ACKNOWLEDGEMENTS}

The financial support provided by Department of Science and Technology under PURSE Scheme, Government of India is gratefully acknowledged. The authors are thankful to Drs. S.E. Dapurkar (Tata Chemicals Limited, Pune) and A. Sakthivel (Delhi University) for providing instrumental facility during catalyst characterization.

\section{REFERENCES}

1. J. Zakzeski, P.C.A. Bruijnincx, A.L. Jongerius and B.M. Weckhuysen, Chem. Rev., 110, 3552 (2010);

https://doi.org/10.1021/cr900354u.

2. P.J. Deuss, M. Scott, F. Tran, N.J. Westwood, J.G. de Vries and K. Barta, J. Am. Chem. Soc., 137, 7456 (2015); https://doi.org/10.1021/jacs.5b03693.

3. A. Rahimi, A. Ulbrich, J.J. Coon and S.S. Stahl, Nature, 515, 249 (2014); https://doi.org/10.1038/nature13867.

4. S. Jia, B.J. Cox, X. Guo, Z.C. Zhang and J.G. Ekerdt, Ind. Eng. Chem. Res., 50, 849 (2011); https://doi.org/10.1021/ie101884h.

5. J.C. Wozniak, D.R. Dimmel and E.W. Malcom, Institute of Paper Science and Technology, Paper series No. 349, pp. 1-62 (1990).

6. D. Cedeno and J.J. Bozell, Tetrahedron Lett., 53, 2380 (2012); https://doi.org/10.1016/j.tetlet.2012.02.093.

7. C. Canevali, M. Orlandi, L. Pardi, B. Rindone, R. Scotti, J. Sipila and F. Morazzoni, J. Chem. Soc., Dalton Trans., 3007 (2002); https://doi.org/10.1039/b203386k.

8. C. Crestini, A. Pastorini and P. Tagliatesta, J. Mol. Catal. Chem., 208, 195 (2004); https://doi.org/10.1016/j.molcata.2003.07.015.

9. S.K. Badamali, R. Luque, J.H. Clark and S.W. Breeden, Catal. Commun., 12, 993 (2011); https://doi.org/10.1016/j.catcom.2011.02.025.

10. S.K. Badamali, R. Luque, J.H. Clark and S.W. Breeden, Catal. Commun., 10, 1010 (2009); https://doi.org/10.1016/j.catcom.2008.12.051.

11. K. Schumacher, M. Grün and K.K. Unger, Micropor. Mesopor. Mater, 27, 201 (1999); https://doi.org/10.1016/S1387-1811(98)00254-6. 
12. W. Zhan, Y. Guo, Y. Wang, X. Liu, Y. Guo, Y. Wang, Z. Zhang and G. Lu, J. Phys. Chem. B, 111, 12103 (2007); https://doi.org/10.1021/jp0745211.

13. S. Gomez, L.J. Garces, J. Villegas, R. Ghosh, O. Giraldo and S.L. Suib, J. Catal., 233, 60 (2005); https://doi.org/10.1016/i.jcat.2005.04.015.

14. K. Schumacher, P.I. Ravikovitch, A. Du Chesne, A.V. Neimark and K.K. Unger, Langmuir, 16, 4648 (2000); https://doi.org/10.1021/la991595i.

15. A. Corma, A. Martínez, V.M. Soria and J.B. Montón, J. Catal., 153, 25 (1995); https://doi.org/10.1006/jcat.1995.1104.

16. J. Rathouský, A. Zukal, O. Franke and G. Schulz-Ekloff, J. Chem. Soc., Faraday Trans., 91, 937 (1995); https://doi.org/10.1039/FT9959100937.

17. A. Corma, Chem. Rev., 97, 2373 (1997); https://doi.org/10.1021/cr960406n.

18. D.T. On, D. Desplantier-Giscard, C. Danumah and S. Kaliaguine, Appl. Catal. A, 222, 299 (2001); https://doi.org/10.1016/S0926-860X(01)00842-0.

19. H. Li, S. Wang, F. Ling and J. Li, J. Mol. Catal. Chem., 244, 33 (2006); https://doi.org/10.1016/j.molcata.2005.08.050.

20. S.S. Bhoware, K.R. Kamble and A.P. Singh, Catal. Lett., 133, 106 (2009); https://doi.org/10.1007/s10562-009-0162-1.

21. S.V. Sirotin and I.F. Moskovskaya, Petrol. Chem., 49, 99 (2009); https://doi.org/10.1134/S0965544109010186.

22. R. Sadual, S.K. Badamali, S.E. Dapurkar and R.K. Singh, World J. Nanosci. Eng., 5, 88 (2015); https://doi.org/10.4236/wjnse.2015.53011.

23. R. Sadual, S.K. Badamali and R.K. Singh, Adv. Por. Mater., 2, 48 (2014); https://doi.org/10.1166/apm.2014.1044.

24. S.K. Badamali, J.H. Clark and S.W. Breeden, Catal. Commun., 9, 2168 (2008); https://doi.org/10.1016/j.catcom.2008.04.012.

25. F.A. Cotton, G. Wilkinson, C.A. Murillo and M. Bochmann, Advanced Inorganic Chemistry, Wiley: New York, edn 6 (1999).

26. V.P. Shiralkar, C.H. Saldarriaga, J.O. Perez, A. Clearfield, M. Chen, R.G. Anthony and J.A. Donohue, Zeolites, 9, 474 (1989); https://doi.org/10.1016/0144-2449(89)90041-9.

27. V. Alfredsson and M.W. Anderson, Chem. Mater., 8, 1141 (1996); https://doi.org/10.1021/cm950568k.

28. C.T. Kresge, M.E. Leonowicz, W.J. Roth, J.C. Vartuli and J.S. Beck, Nature, 359, 710 (1992); https://doi.org/10.1038/359710a0.
29. S.C. Laha, P. Mukherjee, S.R. Sainkar and R. Kumar, J. Catal., 207, 213 (2002); https://doi.org/10.1006/jcat.2002.3516.

30. J. Panpranot, S. Kaewkun, P. Praserthdam and J.G. Goodwin Jr., Catal. Lett., 91, 95 (2003); https://doi.org/10.1023/B:CATL.0000006323.17873.78.

31. P.J. Branton, P.G. Hall and K.S.W. Sing, J. Chem. Soc. Chem. Commun., 1257 (1993); https://doi.org/10.1039/c39930001257.

32. S.J. Gregg and K.S.W. Sing, Adsorption, Surface Area and Porosity, Academic Press: New York, edn 2 (1982).

33. J. Xu, Z. Luan, H. He, W. Zhou and L. Kevan, Chem. Mater, 10, 3690 (1998); https://doi.org/10.1021/cm980440d

34. K.S.W. Sing, D.H. Everett, R.A.W. Haul, L. Moscou, R.A. Pierotti, J. Rouquerol and T. Siemieniewska, Pure Appl. Chem., 57, 603 (1985); https://doi.org/10.1351/pac198557040603.

35. U.S. Taralkar, P. Kalita, R. Kumar and P.N. Joshi, J. Appl. Catal. A, 358, 88 (2009); https://doi.org/10.1016/j.apcata.2009.02.001.

36. D. Kaucky, J. Dedecek and B. Wichterlova, Micropor. Mesopor. Mater, 31, 75 (1999); https://doi.org/10.1016/S1387-1811(99)00058-X.

37. S. Lim, D. Ciuparu, Y.H. Yang, G. Du, L.D. Pfefferle and G.L. Haller, Micropor. Mesopor. Mater., 101, 200 (2007); https://doi.org/10.1016/j.micromeso.2006.11.002.

38. Q. Zhao, J.Y. Chu, T.S. Jiang and H.B. Yin, Colloids Surf. A Physicochem. Eng. Asp., 301, 388 (2007); https://doi.org/10.1016/j.colsurfa.2007.01.002.

39. E.M. Flanigen, H. Khatami and H.A. Szymanski, eds.: E.M. Flanigen and L.B. Sand, Molecular Sieve Zeolites, ACS Advance Chemical Series vol. 101, American Chemical Society, Wasington, DC, p. 201 (1971).

40. C.Y. Chen, H.X. Li and M.E. Davis, Micropor. Mater, 2, 17 (1993); https://doi.org/10.1016/0927-6513(93)80058-3.

41. S. Patai and Z. Rappoport, The Chemistry of Quinonoid Compounds, Wiley: New York, vol. 2 (1988)

42. H.R. Bjørsvik and L. Liguori, Org. Proc. Res. Dev., 6, 279 (2002); https://doi.org/10.1021/op010087o.

43. R. Sheldon, eds.: R.A. Sheldon, and J.K. Kochi, Metal Catalysed Oxidation of Organic Compound, Academic Press, New York, p. 373 (1981).

44. T. Baskaran, R. Kumaravel, J. Christopher and A. Sakthivel, RSC Adv., 4, 11188 (2014); https://doi.org/10.1039/c3ra46703a. 